\title{
Analysis of Chinglish Phenomena and Strategies for Chinese-English Translation of Thesis Abstract
}

\author{
Weifeng Wang \\ Changchun University of Finance and Economics Changchun, China \\ 39947235@qq.com
}

Keywords: Chinglish phenomena; English-Chinese translation; cultural differences: strategies

\begin{abstract}
It is found that there are many Chinglish phenomena in abstract of undergraduate's abstract. The biggest challenge that students encounter is to find authentic and idiomatic way to translate the original Chinese text into English. To solve the problem, this paper analyses the causes of Chinglish phenomenon and offers the solutions to the problem with empirical method. The research method goes as follows: the first step is to analyze the cause of Chinglish phenomenon with the method of case analysis; the second step is to list the different expressions between Chinese and English, and then to research the Chinglish from words and sentence levels based on corpus analysis. In Chinese-English translation, the culture and thinking difference between Chinese and English have the most significant influence on translators' expression, which makes it hard to accurately translate the meaning of the original Chinese text. The importance of the paper lies in making those people that including researchers, translators and other English learners recognize the existence of the problem and pay more attention to it, thus help to improve students' competency in abstract writing and translating.
\end{abstract}

\section{Introduction}

With the deepening of reform and opening policy, English has already become more important and more widely used throughout china. English in China has already been designated as the first foreign language and a compulsory subject for all the students to learn in primary and secondary schools and even in universities. The nativization of English in China has evolved a special variety China English, which is deeply influenced by Chinese language and culture widely accepted by Chinese people and native English speakers. However, Chinglish is a kind of deformed language formed by the Chinese English learners in the unique environment, and it is known as the English with Chinese characteristics. Its emergence must have certain inevitability and it has caused a lot of inconvenience to the majority of Chinese people when they learn English. It is an essential phase for Chinese people to learn and use English and has its own internality and law. Chinglish is English with Chinese phonetics, grammar, vocabulary characteristics in another words, it is a language with Chinese characteristics, which Chinglish is a mixture of Chinese and English.

The thesis aims to check on the application of Chinglish to the Chinese-English translation in abstract. In the process, the thesis makes an analysis of Chinglish and comparison of Chinglish and idiomatic English. It is also available to find discussion of application of the translation measures for abstract. There was evidence that the study of Chinese-English translation in abstract will help to improve domestic deficiency of the theoretical system in the field of writing translation. Chinese students learn English in Chinese environment; therefore, the Chinglish of Chinese-English translation is not only affected by the structure of grammar, but also the Chinese way of thinking is added in the unconscious Chinese customs. In fact, whether in oral or writing translation both include the reaction of the second language learners' mother tongue culture mode of thinking. To strengthen the learner's mother tongue thinking by writing words, at the same time, strengthen the learners understanding of connotation and structure of the native language. As is known to 
all, there is a big the connotation of difference between Chinese and English. This thesis will make contributions to the research on the translation from Chinese to English.

\section{Chinglish Phenomena in Chinese-English Translation}

Recently, English has been paid more attention by Chinese teachers and students with the requirement of written expression in various kinds of English tests. However, there are some phenomena which are confused thinking, broken language and not to the point in college students' translation. The basic reason of this problem is that the translator cannot get out of his Chinese thinking mode and often makes mistakes such as: Good good study, day day up, which is called Chinese style English or Chinglish. Chinese style English is defined as English with Chinese characteristics, which is a combination of English and Chinese. The definition generally accepted by domestic scholars refers to a kind of English for English learners and users in China who forcedly add some Chinese rules and habits during using English because of the effects and interruption of mother language, as a result, they always create some expressions the not comply with standard and cultural habits of English. China's Qing dynasty scholar and translator Yan Fu set three criteria of translation: faithfulness, expressiveness and elegance, which can be explained as the translation should be faithful to the original, and be smooth, and be in accordance with the habits of target language. But there are obvious Chinglish or the Chinese style English which obeyed English traditional expression appearing in students' translation due to the influence of Chinese culture as well as thinking mode, which greatly affects the students' comprehensive capacity of using English. We should highly focus on this kind of problem in translation process.

\section{Causes of Chinglish}

\subsection{Influenced by Native Culture and Thinking.}

Language is the best carrier of our history, culture and spirit; cultural differences will be the bridge between languages. Language is the carrier of thinking; thinking is the language content, if thought mode is Chinese, even if the use of English as a carrier, it is inevitable for translator to produce Chinglish. Chinese thinking mode and that of the western countries have great differences. As Chinese tradition, people do not pay attention to logic that leads to pay less attention to reasons order. Performance in the writing, the Anglo Americans used to come to the point, the most important thing that is putting in the front row. However, the Chinese favor to make conclusions at last.

\subsection{Influenced by the Native Language.}

Chinglish is a common problem in Chinese English translation. This is reflected in two aspects. The primary reason is the difference between these two kinds of languages, Chinese and English. Such as cultural differences, thinking differences.

That "Asian" and "westerners" have fundamentally different thought processes that these can be defined and measured and that, in general, westerners think in terms of objects and logic,

while Asians think in terms of substances and relationships. Although English is widely used in China, but China translators who really mastered the language are few, which caused the Chinglish spread to a certain extent, having a negative effect on the exchanges between China and foreign countries. The other reason is that the Chinese and English belong to Indo European and Sino-Tibetan languages respectively. English is a synthetic language which grammar relation mainly through morphological changes itself to express, while Chinese belongs to analytic language, which grammar relations are mainly expressed by means of vocabulary and word order. There's a big difference between Chinese and English. In learning, students will be unconsciously compared native language with English language that produces positive transfer. Let students better grasp the language of regularity, and produce negative transfer or interference. 


\section{Analysis of Chinglish in Abstract Translation}

\subsection{Grammar-Based Sentences VS. Meaning-Based Sentences.}

China's linguist Wang Li (1994) has once said that: "Given the structure of sentence, the western language is the rule by law, but the Chinese language is the rule by people.” The difficult point of translating lies in the complex structure and the abstract expression. We can change the structure from long sentences to short sentences, from clauses to compound sentences with the analysis of sentence structure. The abstract expression requires translators have a good understanding of the original and a perfect presentation in Chinese. On the one hand, English pays much attention to sentence structure. On the other hand, English likes using ellipsis. There are various kinds of ellipsis in the English language, such as the omission of nouns, verbs, syntax and also scene. In the parallel structure, English often omitted what has appeared in front of the passage, while Chinese tended to repeat these words that were omitted.

\subsection{Long Sentences VS. Short Sentences.}

English is the language of "rule by law", many meanings often can be expressed in a long sentence if there are no errors in the structure. On the contrary, in the Chinese language, semantic meaning can be expressed directly by words and phrases because of Chinese's "rule by people”.

In English sentences, a long modifier can be used in simple sentences to make it long sentences, and make sentences complicated by using the clauses in them. And these clauses will connect with the main clauses or other clauses by guide words, which make the sentence as a whole in nature, complicated apparently, though. There are many short sentences in Chinese whose structure is relatively loose, and some clauses that are changed into compound sentences when translated into Chinese. English tends to use nouns and preposition in the sentence, while Chinese, verbs.

We have some personal pronouns in English such as "we, you and he, they", etc, as well as relative pronouns, "which, that, and so on".

\section{Analysis of the Phenomena of Chinglish}

Chinglish or inter-language for language learners is a stage in the process of language acquisition. In china, most English learners have been studying English since their middle school. That is to say, most of them have a good knowledge of Chinese and a basic understanding of Chinese culture before their English learning. In the process of acquisition, most learners will learn English with the effect of their previous Chinese. So what they learn is a special kind of English, Chinglish. In the translation, the influence of language acquisition is more obvious and leads to the Chinglish. Because of the fundamental differences between English and Chinese, there comes to Chinglish when Chinese syntax and expression are translated into English incorrectly. When it comes to Chinglish, a kind of language which is influenced by mother tongue in Chinese-English translation, it becomes an expression that neither obeys the English language laws nor English common rules. Chinglish is affected so deeply by Chinese thoughts that neither Chinese nor Englishmen can understand it, which will do harm to cultural exchange between china and western countries. The existence of Chinglish makes translation hard to understand and it becomes one of the key problems in Chinese-English translation.

Strategies. The learner's language ability decides the quality of Chinese-English translation. Chinglish occurred mainly because the basic skills of language are not solid in students' translation exercises. It is very important for teaching that must start from the foundation of grammar, vocabulary training inside and outside the class. In English, there are plenty of different pronunciations of the same meaning of vocabulary. Especially it is difficulty to choose in some appropriate words.

English and Chinese syntactic structures are very different. English sentence is used to express emphasis at the beginning of a sentence, but Chinese is the opposite that put the most important part at the end of the sentence. Therefore, in the usual process of teaching to 
strengthen the training of the corresponding sentence structure in Chinese-English translation is important.

After almost ten years of English study, most Chinese students have mastered a large vocabulary and comprehend more basic grammar knowledge. The cultivation of English thinking mode is a very important factor in language communication, beginners usually uses the Chinese sentence patterns to write papers in English and then in accordance with the word for word translation of Chinese sentences follow the prescribed order which are not in the idiomatic English sentences orders. Started learning English and planning to consider the issue of training in English thinking mode. To understand the Western way of thinking, habits and cultural differences in the basic vocabulary of the familiar, the right translation methods should be determined according to situation and context specific. Generally speaking, to improve the overall input language for Chinese learners, speaking, writing and translating trainings are the factors of the effective training of Chinese-English translation.

\section{Conclusion}

Chinglish is a common problem in Chinese-English translation. The primary reason is the difference between these two kinds of languages, Chinese and English. Although English in China is being popularized, there are few translators who have really mastered the English, which causes the Chinglish spread to a certain extent and has a negative effect on the exchanges between China and foreign countries. Therefore, the study Chinese-English translation in abstract of undergraduate is very necessary. In this paper, from perspective of sentence structure, Chinglish in Chinese-English translation is common to see the analysis of the main differences between Chinese and English in sentence structure, this paper discusses a series of Chinglish phenomenon and put forward the corresponding solutions. In the process of Chinese-English translation, "Chinglish" phenomenon has been a neglected spread of the trend. However, if you don't know cause of the problem is very difficult to notice and corrected. Then, even though there are fundamental differences between English and Chinese. Further, the Chinese way of thinking is expressed in the attitudes and ideas. So, it is easy for Chinese-English translators to produce the Chinglish expressions.

\section{References}

[1]. Bachman LF. Fundamental Considerations in Language Testing [M]. Shanghai: Shanghai Foreign Language Education Press, 1999.

[2]. Bright William. International Encyclopaedia of Linguistics[M]. London: Oxford University Press, 1992.

[3]. Ellis R. The Study of Second Language Acquisition [M]. London: Oxford University Press, 1994.

[4]. House Juliane. The Pragmatics of Translation [M]. Shanghai: Shanghai Foreign Language Education, 2001.

[5]. James Carl. Contrastive Analysis [M]. Essex: Longman Group Ltd, 1980.

[6]. James, C. Errors in Language Learning and Use: Exploring Error Analysis[M]. London: Longman, 1998. 